\title{
O TRABALHO PEDAGÓGICO COM SENTIMENTOS EM UMA INSTITUIÇÃO DE ACOLHIMENTO INFANTIL
}

\author{
Bruna Ercoles da SILVA ${ }^{1}$ \\ Cristina Satiê de Oliveira PÁTARO \\ Ricardo Fernandes PÁTARO
}

\begin{abstract}
Resumo
O presente texto é resultado de pesquisa e visa discutir a necessidade de um trabalho pedagógico em instituições de acolhimento infantil. A pesquisa foi desenvolvida em uma Casa-Lar da região de Campo Mourão, no estado do Paraná, durante um projeto de pesquisa de extensão universitária realizado por professoras(es) e alunas da Universidade Estadual do Paraná - Unespar. A ação foi desenvolvida com crianças acolhidas de idade entre 4 e 11 anos. Para compor esse artigo, apresentamos o percurso histórico que envolve a institucionalização de crianças e adolescentes no Brasil, mais especificamente o Brasil Colônia (1500-1822), Brasil Império (1822-1889), primeiros anos do Brasil República (1889-1980) e o Brasil República a partir das leis em torno aos direitos infantis (1980-2019). Além disso, apresentamos a instituição de acolhimento como espaço educativo, que necessita da atuação de pedagogas(os). Também apresentamos o recorte de uma prática pedagógica desenvolvida em uma Casa-Lar com atividades atreladas aos sentimentos de crianças e adolescentes abrigadas(os). Os resultados indicam que esse tipo de trabalho se faz necessário para proporcionar um desenvolvimento afetivo, social, cognitivo e psíquico a crianças abrigadas e, assim, amenizar os efeitos causados pelo afastamento familiar.
\end{abstract}

Palavras-chave: Instituições de acolhimento. Crianças em situação de vulnerabilidade. Papel pedagógico. Sentimentos. Extensão universitária.

\footnotetext{
${ }^{1}$ Bruna Ercoles da Silva é pedagoga pela Universidade Estadual do Paraná - Unespar (2018), mestranda no Programa de Pós-Graduação Interdisciplinar Sociedade e Desenvolvimento PPGSeD/Unespar e bolsista CAPES.

E-mail: brunnaercoles@gmail.com

${ }^{2}$ Cristina Satiê de Oliveira Pátaro é professora do Centro de Ciências Humanas e Educação e do Programa de Pós-Graduação Interdisciplinar Sociedade e Desenvolvimento - PPGSeD/Unespar. Doutora em Educação pela Universidade de São Paulo - USP (2011), mestre em Educação pela Universidade Estadual de Campinas - Unicamp (2006) e pedagoga pela Universidade Estadual de Campinas - Unicamp (2001).

E-mail: crispataro@gmail.com

${ }^{3}$ Ricardo Fernandes Pátaro é professor do Centro de Ciências Humanas e Educação e do Programa de Pós-Graduação Interdisciplinar Sociedade e Desenvolvimento - PPGSeD/Unespar. Doutor em Educação pela Universidade Estadual de Maringá - UEM (2015), mestre em Educação pela Universidade Estadual de Campinas - Unicamp (2008) e pedagogo pela Universidade Estadual de Campinas - Unicamp (2001).

E-mail: ricardopataro@gmail.com
} 


\title{
A PEDAGOGICAL WORK WITH FEELINGS IN A CHILD CARE INSTITUTION
}

\author{
Bruna Ercoles da SILVA \\ Cristina Satiê de Oliveira PÁTARO \\ Ricardo Fernandes PÁTARO
}

\begin{abstract}
We intend, through this work, to discuss the educator's action at childcare institutions through an experience carried out in a childcare in the region of Campo Mourão - PR during a university extension project carried out by members of Paraná State University. The research was developed with children from 4 to 11 years old. In order to accomplish this article, we will show the historical route that involves the children and teenager institutionalization in Brazil aiming at analyzing the perception one had about children development at different times: Brazil Colony (1500-1822), Brazil Empire (1822-1889), first years of Brazil Republic (1889-1980) and the Brazil Republic from laws around children's rights (1980-2019). In addition, we present the childcare institution as an educational space, which requires the work of pedagogues. We also present an outline of a pedagogical practice developed in a childcare institution with activities linked to the feelings of sheltered children and adolescents. The results indicate that this type of work is necessary to provide an affective, social, cognitive and psychic development to sheltered children and, thus, to mitigate the effects caused by family distance.
\end{abstract}

Keywords: Childcare Institutions. Vulnerable children. Pedagogical role. Feelings. University extension. 


\section{Introdução}

Historicamente, no Brasil, crianças abandonadas em situação de vulnerabilidade foram sendo vistas com um olhar discriminatório pela sociedade. Desde o Brasil Colônia, quando eram deixadas nas rodas dos expostos para serem criadas por religiosos ou no período do Império no qual lhes eram ensinados ofícios até o período da República, essas crianças e adolescentes foram colocadas à margem do desenvolvimento coletivo. Inicialmente (Colônia e Império) com um caráter assistencialista e logo (início da República) com um caráter repressivo, as instituições criadas não objetivavam a educação de seus acolhidos, pelo contrário, o principal objetivo era retirá-las da convivência comunitária.

A partir do final da década de 1980 e início da década de 1990, as discussões a respeito da infância chegaram até o âmbito institucional e as crianças, que antes permaneciam à margem, passaram a ser entendidas como cidadãos e cidadãs de direitos. Leis foram criadas para garantir que tais direitos fossem efetivados e quando violados pela primeira instituição responsável pelas crianças - família - é dever do Estado e da sociedade assegurá-los. Com isso, as instituições de acolhimento passaram a ser um lugar responsável por assegurar esses direitos, e se mostraram com um grande potencial educativo.

Como locais que visam a educação, as instituições de acolhimento se caracterizam como espaços de educação não-formal, nos quais o(a) pedagogo(a) pode exercer um importante papel na elaboração de práticas que objetivam o desenvolvimento das crianças em suas diferentes dimensões. A partir do projeto de extensão realizado pela Universidade Estadual do Paraná - Unespar em parceria com uma Casa-Lar no município de Campo Mourão/PR, percebemos que, durante a convivência cotidiana, acontecem diversas situações que podem permitir o desenvolvimento cognitivo, afetivo, moral, ético, etc. dos(as) acolhidos(as).

A partir do caráter educativo das instituições de acolhimento - adotado nesse trabalho - discutiremos o papel do(a) pedagogo(a) nos espaços de educação não-formal, perpassando por um breve-histórico que nos auxilia na concepção atual das crianças acolhidas, bem como as leis que as envolvem, por fim, apresentaremos uma prática desenvolvida em uma Casa-Lar da região de Campo Mourão - PR.

\section{Histórico das instituições de acolhimento infantil no Brasil}

Atualmente, em termos legais, podemos afirmar que crianças e adolescentes “[...] gozam de todos os direitos fundamentais inerentes à pessoa humana.” (BRASIL, 1990). As leis do Estado brasileiro - especialmente o Estatuto da Criança e do Adolescente (ECA), de 1990 -, asseguram que esses direitos fundamentais sejam efetivados, sobretudo em situações de descumprimento de tais direitos. O acolhimento institucional, foco deste artigo, é uma das maneiras de garantir proteção e abrigo a crianças e adolescentes enquanto não podem retornar às suas famílias, por exemplo. Entretanto, o entendimento de que crianças e adolescentes são 
cidadãos e cidadãs de direitos é uma conquista recente. O próprio ECA tem pouco mais de 30 anos e, por muito tempo, as crianças foram entendidas como seres meramente biológicos, adultos em miniatura, desprovidos de um estatuto social (ARIÈS, 1986). Embora Ariès tenha se dedicado à história das crianças europeias, podemos afirmar que essa concepção de infância também vigorou no Brasil, já que nosso país sofria influências diretas da Europa. Assim, é somente a partir do século XVII que a infância, ou pelo menos aquela de famílias nobres - como apontam as pesquisas de Ariès (1986) -, passou pouco a pouco a ser considerada um período da vida que exige cuidados especiais, diferentes daqueles direcionados aos adultos. Um dos elementos que indicam essa mudança, afirma Ariès, é a presença maior, nas pinturas e quadros, de crianças representadas com trajes que a distinguiam dos adultos, o que não ocorria na Europa com a mesma frequência antes do século XVII.

No Brasil, é possível destacar a evolução do sentimento de infância (ARIÈS, 1986) e a trajetória histórica das instituições de acolhimento infantil em quatro momentos centrais de nossa história: Brasil Colônia (1500-1822), Brasil Império (1822-1889), primeiros anos do Brasil República (1889-1988) e o Brasil República até a contemporaneidade, este último já a partir do entendimento das crianças e adolescentes como cidadãos de direitos (19882020). Para compreender a importância da legislação atual em proteção à infância, consideramos importante retomar cada um desses quatro momentos de nossa história, como passaremos a abordar a partir de agora.

Em um primeiro momento, durante o período colonial (1500-1822), é necessário destacar que as leis que regiam as políticas públicas no Brasil eram ditadas diretamente de Portugal. Isso se dava em todos os âmbitos da sociedade, inclusive no que tange às infâncias. A princípio, com o trabalho desenvolvido pelos jesuítas portugueses, surgiu no Brasil o início de um sentimento de particularidade infantil, ou seja, as crianças passaram a ser vistas como seres diferentes dos adultos. Em seus estudos, Ariès (1986) menciona a Companhia de Jesus - que possuía missões não só no Brasil, mas em vários países - e destaca o entendimento dos padres jesuítas a respeito das particularidades da infância e dos cuidados necessários com as crianças. Chegando ao Brasil para catequizar os povos indígenas, os padres da ordem jesuíta criaram casas de recolhimento, no intuito de cuidar e catequizar as crianças (BERGER, 2005). Com a escravidão no Brasil na metade do século XVI, os padres jesuítas passaram a acolher e ensinar ofícios também a crianças fruto de relacionamentos entre escravas e senhores.

A partir do século XVII, com a expulsão dos jesuítas por Marquês de Pombal, as instituições religiosas passaram a se ocupar diretamente das crianças e adolescentes. Em 1726, havia muitas crianças abandonadas no Brasil. Tais crianças eram deixadas nas portas de igrejas e casas, algumas chegavam a ser devoradas por animais (RIZZINI; PILOTTI, 2009). Essa situação preocupou o vice-rei Vasco Fernandes César de Menezes, mais conhecido como Conde de Sabugosa, que adotou as "rodas dos expostos" ou "rodas dos enjeitados" cilindros junto as Santas Casas de Misericórdia nos quais eram deixadas as crianças para 
serem recolhidas, já que a palavra “abandono” não era usada naquela época (BERGER, 2005; RIZZIZI, RIZZINI, 2004). Essa medida, embora novidade na colônia brasileira, já estava sendo combatida no continente europeu, pois uma das consequências de seu uso foi a banalização e o aumento do número de crianças rejeitadas pelas famílias. Isso pode ser comprovado quando constatamos que somente entre os anos de 1852 e 1853 foram deixadas aproximadamente 560 crianças nas rodas existentes no Brasil. Ainda que avaliadas negativamente, as rodas dos expostos foram extintas somente na metade do século $\mathrm{XX}$ (RIZZINI, RIZZINI, 2004; NEJAR, 2011). O serviço prestado pela roda durava em média 7 anos e depois disso as crianças ficavam a mercê de uma ordem judicial que decidia seu destino de acordo com os interesses, geralmente relacionados ao trabalho precoce, de quem as quisesse manter. Muitas, no entanto, não chegavam sequer a essa idade, visto que a taxa de mortalidade era altíssima, chegando a 70\% das crianças da época (RIZZINI, PILOTTI, 2009).

Com visível caráter religioso, as medidas adotadas no período colonial não visavam, em sua essência, a formação das crianças abandonadas, mas o " [...] interesse de proteger a honra privada, escondendo-se a ilegitimidade com um véu assistencialista e religioso, ao mesmo tempo facilitador do trabalho doméstico.” (BERGER, 2005, p. 171). Dessa forma, a maioria das crianças deixadas nas rodas não eram escravas - as quais eram vendidas -, mas sim crianças brancas, fruto de adultério, pobreza extrema e orfandade. Em meio aos elementos religiosos e de caridade envolvidos, podemos observar que as instituições de acolhimento surgem no Brasil carregadas de uma atmosfera de condenação moral e assistencialismo, o que se intensificou nas décadas seguintes.

Já durante o período Imperial no Brasil (1822-1889), o assistencialismo se expandiu com a criação em massa de asilos. O principal objetivo foi proporcionar educação industrial a meninas e meninos, fossem órfãs(ãos), abandonadas(os) ou indigentes (RIZZINI, RIZZINI, 2004; RIZZINI, PILOTTI, 2009). O caráter dos asilos pressupunha a segregação do meio social ao qual pertenciam as crianças, uma intensa disciplina e o ensino de ofícios. Foram instaladas casas de instrução (primária, musical, religiosa e ofícios mecânicos) e, no caso das meninas órfãs legítimas, foram criados colégios com o objetivo de ensinar afazeres domésticos. Essas práticas permaneceram até o fim do Brasil Império (1889) e existiram fortemente também durante o início da República.

No período histórico seguinte, os primeiros anos do Brasil República (1889-1988), aquele assistencialismo repressivo que marcou o Brasil Império foi mantido, entretanto, com um caráter aparentemente filantrópico higienista, além de repressivo, como era visível nos reformatórios e casas de correção. Após os primeiros anos do Brasil República, já no início do século $\mathrm{XX}$, fatores como a libertação dos escravos, o crescimento da industrialização e uma maior concentração de pessoas nas áreas urbanas, levaram ao surgimento de uma classe marginalizada, com a intensificação da inserção precoce das crianças no mundo do trabalho, muitas vezes em situações sub-humanas, elevando assim as taxas de mortalidade e comprometendo o projeto econômico da burguesia em ascensão 
(PARANÁ, 2013). As ideias higienistas chegaram ao país na intenção de fazer com que a recém-formada República se desenvolvesse. Medidas como a criação de institutos de proteção ao menor, ambulatórios e dispensatórios foram algumas das tentativas de "limpar" as ruas, ou seja, preservar a ordem social e moral sem, contudo, garantir que as crianças que se encontravam em situação de vulnerabilidade tivessem a possibilidade de serem formadas e educadas.

Ao longo do século XX, o número de crianças nas ruas aumentou e o Estado brasileiro viu nascerem as primeiras iniciativas para instaurar medidas legais e organizar um projeto de assistência à infância, como o $1^{\circ}$ código de menores em 1927, que tinha por objetivo cuidar de questões relacionadas à delinquência e abandono infantil. Embora fosse a primeira tentativa sistematizada de proteger a infância, as normas do código apresentavam um caráter fortemente discriminatório e associavam pobreza à delinquência. Ainda que pioneira, a iniciativa enfocava normas padronizadas a serem seguidas por toda a população e, quando não eram seguidas, o que se via era uma forte segregação que muito se distanciava das intenções originais do código (BERGER, 2005; RIZZINI, RIZZINI, 2004; RIZZINI, PILOTTI, 2009). Em suma, o que se assistiu foi que as instituições de acolhimento da época adotaram o código e passaram a funcionar dentro de normas desumanas que terminaram por afastar as crianças e adolescentes do convívio em sociedade em vez de protegê-las.

O Serviço de Assistência ao Menor (SAM), criado em 1941 durante o Governo Vargas, foi duramente criticado por seu caráter correcional e repressivo, uma espécie de modelo penitenciário para crianças. O SAM foi substituído em 1964 pela Fundação Nacional do Bem-Estar do Menor (FUNABEM) e pela Fundação Estadual do Bem-Estar do Menor (FEBEM). Tais instituições continuaram sendo regradas por um caráter fortemente repressivo, o que impulsionou a crença equivocada de que o menor abandonado é um delinquente. Nessas fundações, não apenas se encontravam crianças infratoras, mas crianças que por diversas razões estavam em situação vulnerável. Dados de pesquisas realizadas por Rizzini e Rizzini (2004) mostram que entre 80 e 90\% das crianças internadas não havia cometido nenhum ato infrator. No ano de 1966, as fundações abrigavam 70.348 crianças órfãs e em situação de indigência, 8.172 por desvio de conduta, 1.409 com deficiências físicas e mentais e 3.466 por serem filhas de pais tuberculosos e hansenianos. As medidas que foram adotadas durante esses anos para atender ao crescente número de crianças vulneráveis formaram adultos com dificuldade de exercer as potencialidades humanas de maneira plena (RIZZINI, RIZZINI, 2004; PARANÁ, 2013).

A criação do $2^{\circ}$ Código de Menores, em 1979, foi resultado das discussões que estavam entendendo as crianças como cidadãs de direitos e de forma inicial possibilitou lançar um novo olhar para as instituições de acolhimento infantil. No entanto, suas normas também estavam relacionadas a assistência, proteção e vigilância aos menores. Somente com a promulgação da Constituição Federal (1988) e do ECA (1990) é que a 
institucionalização das crianças e adolescentes passou a ser vista com um caráter humanitário e começou a substituir o caráter repressivo pelo educativo.

O último momento histórico que abordamos tem o seu início na década de 1980, período em que foram aprofundadas discussões e debates acerca dos direitos humanos no Brasil. Tais discussões influenciaram as leis promulgadas pela Constituição Federal de 1988 e, a partir das normas preconizadas pela constituição, as leis referentes à institucionalização das infâncias adotaram também o entendimento de que crianças e adolescentes são cidadãos e cidadãs de direitos. Quanto à garantia desses direitos, o artigo 227 da Constituição Brasileira de 1988 afirma que:

É dever da família, da sociedade e do Estado assegurar à criança, ao adolescente e ao jovem, com absoluta prioridade, o direito à vida, à saúde, à alimentação, à educação, ao lazer, à profissionalização, à cultura, à dignidade, ao respeito, à liberdade e à convivência familiar e comunitária, além de colocá-los a salvo de toda forma de negligência, discriminação, exploração, violência, crueldade e opressão. (BRASIL, 1988).

No referido artigo, fica explícito o dever da família, da sociedade e do Estado em garantir os direitos das crianças e dos adolescentes. De igual forma, o ECA também afirma, em seu $4^{\circ}$ artigo que:

É dever da família, da comunidade, da sociedade em geral e do poder público assegurar, com absoluta prioridade, a efetivação dos direitos referentes à vida, à saúde, à alimentação, à educação, ao esporte, ao lazer, à profissionalização, à cultura, à dignidade, ao respeito, à liberdade e à convivência familiar e comunitária. (BRASIL, 1990).

Rumo à superação dos elementos religiosos e de caridade, bem como da atmosfera de condenação moral e de assistencialismo presentes sobretudo no período Colonial e Imperial, o Brasil contemporâneo conta com alguns instrumentos legais para assegurar os direitos de crianças e adolescentes. Além disso, ainda há um salto a ser dado com relação à importância das instituições de acolhimento passarem a ser também um espaço educativo, de preocupação com a formação humana das crianças e adolescentes que passam por ela. É dever do Estado cumprir um papel de proteção e de assegurar que sejam efetivados os direitos estabelecidos. Para isso, em alguns casos as crianças são retiradas de suas famílias e levadas até as distintas modalidades de acolhimento, como abrigos e Casas-Lares, que têm o objetivo de acolhê-las, protegê-las e prepará-las para o exercício da cidadania, ou seja, combater a discriminação e oferecer condições para o seu desenvolvimento psíquico, cognitivo, social, moral, entre outros. Mas, como são organizadas as instituições de acolhimento situadas no estado do Paraná e que foram alvo de nossa pesquisa? Como é possível que tais instituições sejam palco de ações pedagógicas e educativas em benefício de crianças e adolescentes acolhidas(os)? É o que abordaremos a seguir.

\section{Instituições de acolhimento como espaços educativos}

É grande o número de instituições que acolhem crianças e adolescentes no Brasil. De acordo com dados do Cadastro Nacional de Crianças Acolhidas, em 13 de novembro de 
2018 havia 4.449 entidades de acolhimento no país. Dessas, 1.228 estão localizadas no Estado do Paraná, ou seja, quase 30\% do total nacional. Tais instituições atendem crianças e adolescentes de 0 até 18 anos de idade que, em sua maioria, chegam até as entidades por meio de assistentes sociais (TORRES, 2015). De acordo com o inciso $2^{\circ}$ do Artigo 19 da Lei 12.010 de 2009, o tempo de permanência nos abrigos é de até 2 anos, enquanto a situação da(o) abrigada(o) é decidida judicialmente. Algumas vezes, essas crianças retornam para suas famílias biológicas e em outras são encaminhadas para adoção. O que desejamos destacar é que, no período no qual se encontram acolhidas, a lei garante que sejam adotadas medidas que previnam ou reparem possíveis danos causados pelo afastamento familiar, como afirmam Cavalcante e Cruz (2018). Assim, geralmente as instituições de acolhimento infantil são compreendidas como espaços que têm por objetivo colocar crianças e adolescentes “[...] a salvo de toda forma de negligência, discriminação, exploração, violência, crueldade e opressão.” (BRASIL, 1988). Ainda que isso esteja correto, e baseado no artigo 227 da Constituição Brasileira, consideramos importante relembrar que o mesmo artigo, e ainda o ECA (1990), preconizam que o Estado, na falta da família, deve garantir o “[...] direito à vida, à saúde, à alimentação, à educação, ao lazer, à profissionalização, à cultura, à dignidade, ao respeito, à liberdade e à convivência familiar e comunitária.” (BRASIL, 1988, grifos nossos). Diante disso, é coerente entender que as Casas-Lares podem também exercer uma ação enquanto espaços educativos.

De fato, dentre as medidas de proteção aos direitos infantis que exercem os abrigos e casas-lares, ao longo dos últimos anos tem-se verificado uma medida potencial não somente de assistência, mas também educativa. Quando a educação vai além dos espaços escolares e chega até os ambientes de convivência coletiva em seus diferentes contextos, chamamos esses espaços de educação não-formal (CAVALCANTE, CRUZ, 2018; TRILLA, 2008).

Os espaços de educação não-formal foram caracterizados como tal a partir da segunda metade do século XX e surgiram em decorrência de fatores sociais, econômicos e tecnológicos, como o aumento da demanda da educação, as transformações no mundo do trabalho, mudanças na instituição familiar, entre outras (TRILLA, 2008). Uma das características fundamentais dos espaços de educação não-formal é que ocorrem a partir da “[...] necessidade de implementar ações educativas em setores da população em conflito, socioeconomicamente marginalizados, deficientes, etc. [...]” (TRILLA, 2008, p. 20). Nesse contexto, entende-se que as crianças que chegam até os abrigos e casas-lares foram historicamente colocadas à margem da sociedade e estão em situação de conflito e de vulnerabilidade, já que um ou mais de seus direitos foram violados.

Sendo assim, as instituições de acolhimento podem ser entendidas como espaços de socialização e de aprendizagem, ambientes nos quais as crianças e os(as) adolescentes têm a possibilidade de viver experiências significativas que contribuam para o desenvolvimento de suas potencialidades e aprendizagens. O que desejamos destacar, com essa 
argumentação, é que nos espaços de acolhimento podem e devem ser desenvolvidas práticas pedagógicas voltadas para o desenvolvimento físico, psíquico, emocional e cognitivo das crianças e adolescentes. Assim, a instituição de acolhimento “[...] passa a apoiar as crianças não só nas necessidades físicas, de higiene e de alimentação, mas também a ter uma preocupação no que se refere ao seu desenvolvimento social, emocional e educacional, voltado a uma visão cidadania, e assumindo-se como um ambiente socioeducativo.” (TORRES, 2015, p. 9).

Dentre as muitas possibilidades educativas a serem desenvolvidas em instituições de acolhimento, as chamadas Casas-Lares, as práticas pedagógicas relacionadas à construção de valores e à afetividade tem apresentado potencial para o desenvolvimento das crianças e adolescentes acolhidos. Como exemplo, podemos citar a experiência publicada por Nejar (2011) e realizada em duas casas do abrigo João Paulo II, na cidade de Porto Alegre. A pesquisadora - junto com uma equipe interdisciplinar composta por uma assistente social, uma odontopediatra, uma psicóloga, uma pedagoga e duas professoras - elaborou uma série de 8 encontros com diversas ações pedagógicas que tinham por objetivo melhorar o convívio dentro da Casa-Lar. Após a realização das atividades, o grupo percebeu que o trabalho foi positivo, já que os pais e mães sociais passaram a tratar as crianças com afeto e trabalharam as necessidades individuais de cada criança, melhorando assim o convívio social.

Embora seja importante desenvolver trabalhos pedagógicos em instituições de acolhimento, ainda são poucas as pesquisas divulgadas sobre práticas nesses locais. Romanelli (apud CHESINI, 2015) fez um levantamento a respeito de trabalhos de investigação com dados de pedagogas(os) que atuam em instituições de acolhimento e constatou que, entre os anos de 2009 e 2012, somente dois trabalhos abordavam essa temática, enquanto, no mesmo período, foram encontradas quinze pesquisas relacionadas à atuação do(a) pedagogo(a) em outros espaços de educação não-formal, diferentes das casas-lares. Uma das pesquisas foi feita por Izar (2011) e um aspecto que chamou a atenção da pesquisadora foi o fato de se priorizar o cuidado com elementos organizacionais da Casa-Lar e se deixar em segundo plano práticas educativas. De forma semelhante, o Plano Decenal do Estado do Paraná afirma que, dentre os cinco direitos mais violados das crianças e adolescentes que chegam até esses espaços, o segundo com maior causa é o Direito à Educação, à Cultura, ao Esporte e ao Lazer (PARANÁ, 2013). Um dos prejuízos causados pela ausência de ações educativas é a de que “[...] o jovem não se sente compreendido e aceito, e, se isto não ocorre, ele se torna incapaz de compreender e aceitar a si mesmo, inviabilizando qualquer tentativa de levá-lo a aceitar e compreender as demais pessoas” (COSTA, 1999 p. 15 apud IZAR, 2011, p. 119). Dessa forma, ações educativas precisam acontecer para que os sujeitos se reconheçam como tal e desenvolvam suas potencialidades.

Em suma, depois de analisarmos a trajetória histórica das instituições de acolhimento no Brasil, desde a visão religiosa, de caridade, repressiva e permeada por uma 
atmosfera de condenação moral até a contemporânea promulgação de leis - sobretudo a Constituição Federal de 1988 e o ECA de 1990 -, destacamos a importância de entender que crianças e adolescentes são cidadãos e cidadãs de direitos. Ainda que, no Brasil, estejamos longe de uma situação ideal para o desenvolvimento integral das crianças e adolescentes, é necessário continuar defendendo a Constituição e o ECA, sobretudo diante de propostas de redução da maioridade penal que, essencialmente, representam um retorno de concepções repressivas e unicamente policiais. Além dessa defesa dos direitos conquistados ao longo das últimas décadas no Brasil, propomos também que sejam valorizadas as potencialidades educativas das instituições de acolhimento, enquanto espaços de educação não-formal capazes de promover ações pedagógicas que visem o desenvolvimento psíquico, moral, social e cognitivo de crianças e adolescentes acolhidas(os). A esse respeito, dedicaremos as próximas sessões deste artigo, que tem por objetivo apresentar também nossa experiência de pesquisa com a valorização do pedagógico em espaços de acolhimento.

\title{
Sobre a pesquisa na Casa-Lar
}

De início, cabe destacar que a instituição na qual nossa pesquisa foi realizada se define como uma Casa-Lar caracterizada como uma:

\begin{abstract}
Modalidade de Acolhimento Institucional oferecido em unidades residenciais, nas quais pelo menos uma pessoa ou casal trabalha como cuidador residente - em uma casa que não é a sua - prestando cuidados a um grupo de crianças e/ou adolescentes. As casas-lares têm a estrutura de residências privadas, podendo estar distribuídas tanto em um terreno comum, quanto inseridas, separadamente, em bairros residenciais. As casas-lares são definidas pela Lei $\mathrm{n}^{0}$ 7.644, de 18 de dezembro de 1987, devendo estar submetidas a todas as Universidade Estadual de Maringá, 11 a 14 de junho de 2018. 5 determinações do ECA relativas às entidades que oferecem programas de abrigo. (BRASIL, 2008, p. 127).
\end{abstract}

A referida Casa-Lar existe na cidade de Campo Mourão desde a década de 1990. O município não contava com nenhuma instituição que acolhesse crianças até então e, pela iniciativa de um casal de pastores evangélicos e doações de algumas famílias, a casa foi criada. Inicialmente, era mantida por meio de verbas da igreja Luterana e acolhia crianças cujas famílias não possuíam condições de criá-las. Em seu histórico de criação, podemos notar as características anteriormente destacadas por nós, como a presença de um viés religioso e de caridade (elementos presentes nas instituições de acolhimento brasileiras desde o Brasil Colônia). Com o tempo, a referida Casa-Lar passou a receber auxílio financeiro dos governos municipal, estadual e federal - sobretudo com a efetivação de políticas públicas que só se tornaram possíveis com o fortalecimento da Constituição Brasileira e do ECA - e passou a acolher também crianças e adolescentes retirados judicialmente de suas famílias pela violação de um ou mais de seus direitos.

Atualmente, a instituição recebe meninas até 18 e meninos até 12 anos de idade. Essas crianças e jovens são levadas(os) até a Casa-Lar mediante ordem judicial e ficam 
acolhidos enquanto suas famílias biológicas resolvem as questões legais e comprovem ter condições de recebe-las(os) novamente. Nos casos em que isso não seja possível, as crianças e jovens são encaminhadas(os) para adoção. Como mencionamos anteriormente, o tempo de permanência na instituição deve ser de até 2 anos, tempo durante o qual, de acordo com Torres (2015) e Chesini (2014), podem ser desenvolvidas ações pedagógicas que minimizem os prejuízos causados pelo afastamento familiar e também social.

A pesquisa de extensão que aqui apresentamos, vinculada à Universidade Estadual do Paraná - Unespar/Campus de Campo Mourão, foi desenvolvida entre agosto de 2017 e agosto de 2019, contou com o apoio de diferentes profissionais (dois professores pesquisadores, uma aluna bolsista de iniciação científica, estagiárias do curso de pedagogia da instituição e duas pedagogas da Casa-Lar) e teve o objetivo de planejar, desenvolver e acompanhar atividades pedagógicas coletivas e individuais voltadas para crianças e adolescentes acolhidas(os), a fim de proporcionar desenvolvimento cognitivo, afetivo, social e moral. Todas(os) as(os) pesquisadoras(es) envolvidas(os) participaram de diferentes ações práticas na Casa-Lar e, portanto, a pesquisa aqui apresentada pode ser considerada uma pesquisa-ação, ou pesquisa-participante (BRANDÃO, 1981).

A equipe frequentava cotidianamente a Casa-Lar, junto às profissionais que atuam na instituição, não só para realizar diferentes atividades planejadas no âmbito pedagógico da pesquisa - e para destacar a importância do trabalho do pedagogo nas instituições de acolhimento - como também para atender à uma demanda da própria Casa-Lar, que solicitou aos pesquisadores e pesquisadoras que desenvolvessem atividades relacionadas ao acompanhamento de lição de casa, atendimentos diversos, atividades lúdicas e cotidianas. Além disso, o trabalho esteve centrado no atendimento de quatro eixos de pesquisa e registro de atividades: (1) Conhecimento do mundo, pensamento crítico-reflexivo e criatividade; (2) Autoconhecimento, identidade e história de vida; (3) Corpo, afetividade e valores; (4) Convivência, regras e resolução de conflitos. Diante da limitação de espaço, trazemos para discussão nesse artigo algumas das práticas realizadas nos eixos 2 e 3 envolvendo o trabalho com sentimentos. Para tanto, apresentaremos, a seguir, o referencial teórico que fundamentou o trabalho realizado.

\section{Sentimentos como base para o trabalho pedagógico}

Desde a Grécia, encontramos no pensamento ocidental a ideia de que razão e emoção não se relacionam na constituição dos seres humanos. Ao longo de séculos, foram estudados de forma dissociada e fragmentada e, algumas vezes, a emoção foi até mesmo considerada inferior à razão. Embora muitos estudos tenham sido realizados e apontem as intrínsecas relações entre esses polos, ainda é forte em nosso meio a concepção de que razão e emoção estão separadas (PÁTARO; PÁTARO, 2017; SASTRE; MORENO, 2002). 
Essa dissociação está presente em letras de músicas, como nas palavras pronunciadas pela banda Nx Zero ao cantar: “[...] Entre razões e emoções a saída é fazer valer a pena [...]” (FERRERO; ROCHA, 2007). Também encontramos menções à presença da emoção no coração humano em ditados populares como "o coração tem razões que a razão não conhece” e poemas, como “Ao coração que sofre, separado do teu, no exílio em que a chorar me vejo [...]” (BILAC, 2018). São exemplos da dicotomia entre razão e emoção que reforçam a concepção de que cabe ao cérebro pensar e ao coração sentir. De acordo com Sastre e Moreno:

Não fomos preparados para compartilhar nem para resolver com agilidade e de forma não-violenta os problemas que iam surgindo em nossas relações pessoais. Não desenvolvemos a sensibilidade necessária para saber interpretar a linguagem de nossos sentimentos. [...] nossa formação nos tornou mais hábeis para lidar com o mundo físico do que com o social; aprendemos mais coisas do mundo exterior que de nossa própria intimidade, conhecemos mais os objetos que as pessoas do nosso convívio. (SASTRE; MORENO, 2002, p. 19).

Estudos mostram que os aspectos cognitivos e afetivos estão intimamente relacionados, como aponta António Damásio (2012), médico neurologista e neurocientista português que estudou pacientes com lesões cerebrais localizadas no córtex pré-frontal responsável pelo raciocínio - e encontrou em todos esses pacientes uma redução da atividade emocional. Tal verificação o fez concluir que existe uma interação entre razão e emoção e o levou a desenvolver uma teoria que mostra a complexidade das interações entre cognição e emoção, cérebro e corpo. O pesquisador português ainda mostrou que tudo o que acontece no corpo humano reflete no cérebro e vice-versa, ou seja, alguns sentimentos se traduzem em sensações sentidas pelo corpo que terminam por afetá-lo inclusive chegando a deixá-lo enfermo. De acordo com Damásio, a influência dos sentimentos sobre o funcionamento cerebral é muito grande, pois sua presença no cérebro afeta diretamente a elaboração dos pensamentos.

Para Mosquera e Stobäus (2006), “[...] os sentimentos têm a última palavra no que se refere à maneira como o resto do cérebro se ocupa de suas tarefas, em especial a cognição.” (MOSQUERA; STOBÄUS, 2006, p. 126). Segundo os autores, o funcionamento cerebral está intimamente ligado às emoções, contrariando o senso comum que coloca a razão acima dos sentimentos, já que a emoção seria o motor que impulsiona as ações supostamente racionais do ser humano.

De maneira semelhante, o sociólogo francês Edgar Morin, com a teoria da complexidade, afirma que “[...] nada está realmente isolado no universo e tudo está em relação” (MORIN, 1996 p. 274-275). A complexidade não estuda os fenômenos reduzindoos aos seus elementos constitutivos ou superestimando alguns e desprezando outros, pelo contrário, propõe que se entenda a necessidade de olhar para um mesmo objeto de estudo desde uma perspectiva que o perceba em suas diferentes dimensões. No caso da constituição de ser humano, a complexidade nos ajuda a compreender que, embora razão e 
emoção sejam duas dimensões distintas do ser humano, estão relacionadas, já que fenômenos biológicos e psicológicos dialogam, ou seja, são indissociáveis.

No campo da psicologia, os estudos construtivistas têm produzido trabalhos sobre a interação cognição-afetividade e apontado a atuação conjunta dos âmbitos emocionais, racionais, sociais e morais nas concepções, crenças e formas de atuar dos seres humanos (SASTRE; MORENO, 2002). De acordo com Araújo (2007), as ações humanas são resultantes de experiências e valores construídos ao longo da vida de cada um e refletem aquilo que foi resultado de suas interações com o mundo objetivo e subjetivo. Segundo o autor, os valores, por exemplo, se formam a partir de projeções afetivas depositadas por um indivíduo em outro ou em objetos, o que nos mostra mais uma vez a interação entre a razão e a emoção.

Ainda nessa perspectiva, em entrevista concedida a Silva, Rossi e Lanas (2018), a psicóloga Manuela García Quiroga enfatizou que o fato de uma criança estar em uma casa de acolhimento, não garante que ela estará bem, é preciso uma multiplicidade de experiências, de aprendizagens e atividades que auxiliem no estabelecimento de vínculos afetivos e diminuam os sintomas negativos nas condutas e no desenvolvimento emocional das crianças.

Pensando no contexto específico das Casas-Lares, percebemos que nos diversos momentos históricos (Brasil Colônia, Brasil Império, Brasil República) nem sempre foram considerados, com a ênfase necessária, os sentimentos das crianças acolhidas. Entretanto, a partir da concepção que entende as crianças e adolescentes como cidadãos de direitos, podemos destacar a importância de se considerar os sentimentos nos trabalhos pedagógicos voltados para a formação humana. Dessa forma, Sastre e Moreno (2002) propõem uma sequência de atividades com o objetivo de auxiliar as crianças e adolescentes a refletirem acerca de suas ações e sentimentos. Ainda que as autoras tenham proposto tais atividades para o ambiente escolar, entendemos que é fundamental o papel do(a) pedagogo(a) nos espaços de acolhimento, por isso, as atividades propostas também podem ser desenvolvidas no contexto das Casas-Lares, as quais abrigam crianças em situação de vulnerabilidade.

A sequência de atividades proposta por Sastre e Moreno (2002) possui dezoito atividades para trabalhar com os sentimentos de crianças e jovens. As autoras apresentam a alegria e a tristeza como iniciais em um trabalho que pretende abarcar outros sentimentos ao longo do seu processo. Como ponto de partida, indicam a expressão oral e gestual que representam tais sentimentos e dão continuidade por meio do diálogo referente às suas causas. As atividades ainda abrangem a expressão gráfica dos sentimentos por meio do desenho e da escrita e sugerem o compartilhamento coletivo das percepções, a fim de gerar reflexão sobre o que embasa suas ações individuais e as ações dos demais. Em um trabalho mais longo, a sequência de propostas leva as crianças e adolescentes a pensarem inclusive nas formas de intervenção nos sentimentos próprios ou das outras pessoas.

Levando em consideração os pressupostos teóricos aqui apresentados, escolhemos trabalhar com os sentimentos da alegria e da tristeza em uma Casa-Lar da região de Campo 
Mourão - PR, durante o projeto de extensão “Ações pedagógicas voltadas para a formação de crianças e jovens de uma Casa-Lar em Campo Mourão - PR”. Nossa escolha se deu por alguns motivos. Primeiramente, entendemos que ao se encontrarem em um espaço de convivência coletiva distante de suas casas, as crianças e jovens abrigadas(os) necessitavam de práticas para pensar em seus próprios sentimentos. Ao pensar em seus próprios sentimentos, os(as) acolhidos(as) teriam a possibilidade de pensar também criticamente e se desenvolver não apenas emocional, mas cognitivamente.

Além disso, compreendemos a importância de se trabalhar com os sentimentos de crianças abrigadas, já que, muitas vezes consideradas à margem da sociedade, as crianças e adolescentes em situação de vulnerabilidade também correm o risco de permanecerem à margem de si mesmas, tendo dificuldades de se reconhecerem como sujeitos da sua própria história e impedidas de se desenvolverem cognitiva e emocionalmente. Essas questões passarão a ser abordadas a seguir.

\section{A prática pedagógica com sentimentos em uma instituição de acolhimento infantil}

Para iniciar as atividades pedagógicas com sentimentos, utilizamos da proposta inicial de Sastre e Moreno (2002) que tem, entre seus objetivos, utilizar a linguagem oral e gestual como instrumento pedagógico para identificar as manifestações dos sentimentos. Para isso, mostramos às crianças a música "Co co cuá”, da Turma do Balão Mágico. A música retrata - de forma bastante lúdica e apropriada às crianças participantes da atividade (que possuíam entre 4 e 11 anos de idade) - a história de uma galinha que vivia triste em um galinheiro, pois havia engolido um chiclete e passou a cantar diferente das demais galinhas. Entretanto, quando suas amigas a ajudavam, a galinha da música ficava feliz e cantava. Segue abaixo a letra da música.

\section{Co-co-uá - Turma do Balão mágico}

Vou contar uma estória do galinheiro da minha avó Lá todas galinhas juntinhas cantam "C ó - ró - có - có”

Todas, menos uma, que é tão sozinha que até dá dó

Vive só chorando no seu canto, sempre só

Quando era pequena, engoliu um chiclete

Bota o mesmo ovo sem parar

E o galo lhe chama de "iô-iô repete"

Por isso é que ela chora pra cantar "Co-co-uááá co-co-uááa”"

Eu não aguento mais! - Berra a minha avó!

Porque essa galinha não faz mais có-có-ró-có?

Só pra chatear "iô-iô" - Repete sem parar

Co-co-co-Co-Co-coco-co-co-uááá

E quando as galinhas, suas amiguinhas, vêm lhe ajudar

a botar seu ovo, cantar de novo e cacarejar

Grita o papagaio, que é bom de bico e sabe imitar,

Co-Co-uááá co-Co-uááá co-co-co-co-uáááá. 
Após cantar a música algumas vezes com as crianças, lemos a letra e fizemos algumas perguntas como "Por que a galinha não cantava?, Por que ela estava triste?, Quando ela ficava feliz?, Como a galinha manifestava sua alegria e sua tristeza?”. As crianças iam respondendo e, oralmente, concluímos que há coisas que nos deixam tristes e outras que nos deixam felizes. Pedimos então que cada criança dissesse uma coisa que as deixava felizes e outra que as deixava tristes, no intuito de que dialogassem sobre seus próprios sentimentos e dessem início à busca de algumas causas dos sentimentos de alegria e tristeza. Dentre as menções, muitas crianças elencaram motivos relacionados a conflitos presentes em seu cotidiano, como brigas e falta de união. Quanto ao que as deixavam felizes, foram, em grande parte, assuntos relacionados a amizades. Ressaltamos que, de acordo com Sastre e Moreno (2002), nesse momento de diálogo verbal é importante permitir que as crianças se expressem livremente, sem condená-las ou antecipar uma mediação que, caso ocorra em momento inapropriado, pode inibi-las. Por isso, priorizamos escutá-las para então prosseguir com as demais atividades.

Depois do momento inicial, no qual utilizamos a música para começar a pensar em sentimentos e relacionamos verbalmente com momentos alegres e tristes das próprias vidas das crianças, propusemos às crianças que desenhassem ou escrevessem um momento ou algo que as deixava felizes e outro momento que as deixava tristes. Algumas tiveram dificuldade na escrita e optaram pelo desenho, outras crianças escolheram apenas escrever e outras fizeram ainda uso das duas formas de expressão. Vale a pena destacar, como já colocado anteriormente, que as atividades realizadas na Casa-Lar foram planejadas e desenvolvidas por nós, enquanto pedagogas e pedagogos de formação - e em formação -, e tinham o objetivo de levar, para a instituição de acolhimento, atividades educacionais. Um dos objetivos, dentre outros, era trabalhar em eixos que privilegiavam não só um aprendizado conceitual, mais relacionado ao universo escolar, como também um conhecimento do mundo, o pensamento crítico-reflexivo, a criatividade, o autoconhecimento, a afetividade, os valores e a convivência.

Com os desenhos prontos, finalizamos as atividades e montamos coletivamente um varal com os sentimentos relacionados à alegria e à tristeza, os quais ficaram disponíveis e puderam ser vistos pelas demais crianças que não estavam presentes no momento da atividade. Ao verem os próprios desenhos e os de seus colegas, as crianças enxergaram alguns de seus comportamentos ali representados, como os conflitos presentes na Casa-Lar ou os vínculos formados por elas durante a convivência no acolhimento. A seguir, podemos ver alguns exemplos. 


\section{EDUCAÇ̃̃̃}

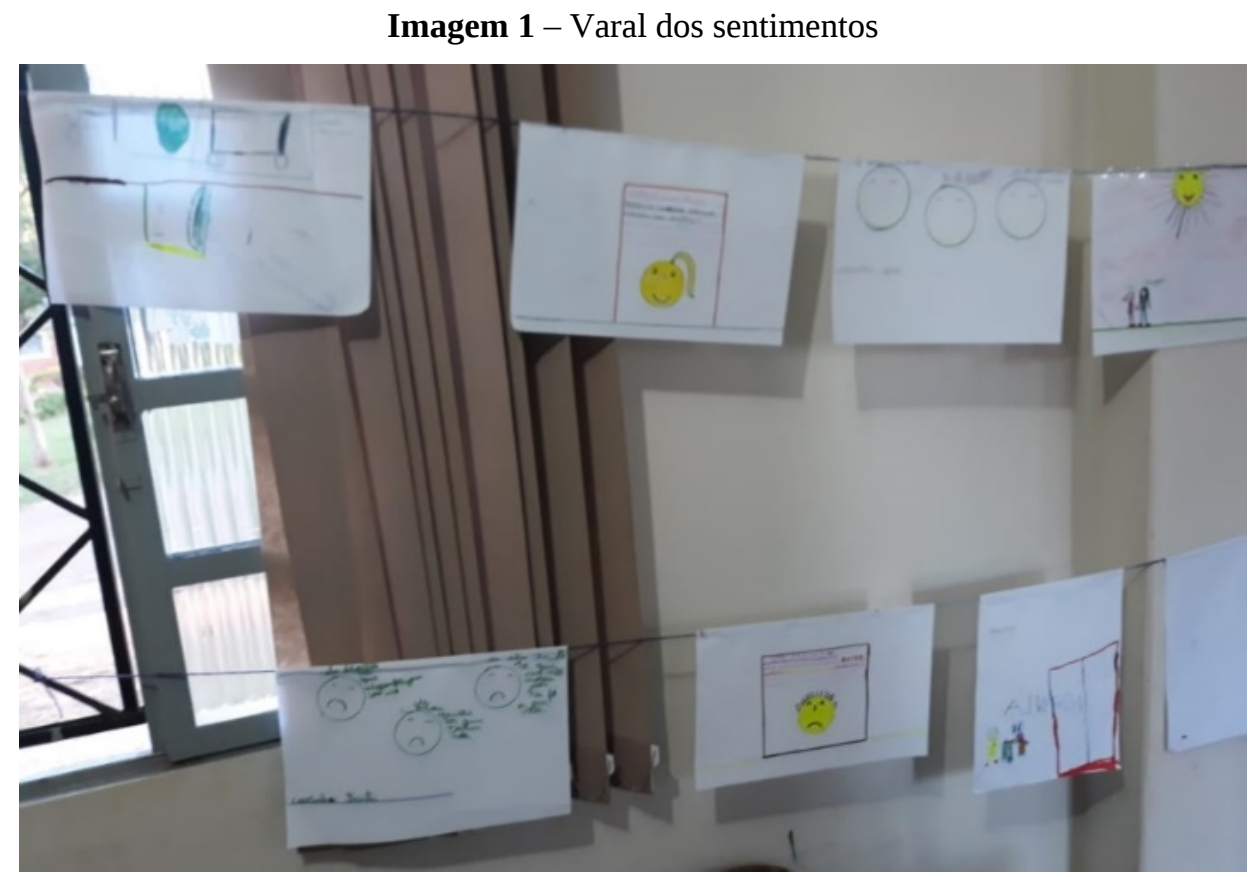

Fonte: Acervo dos(as) pesquisadores(as)

Imagem 2 - Desenho simbolizando a amizade como algo que deixava a criança feliz

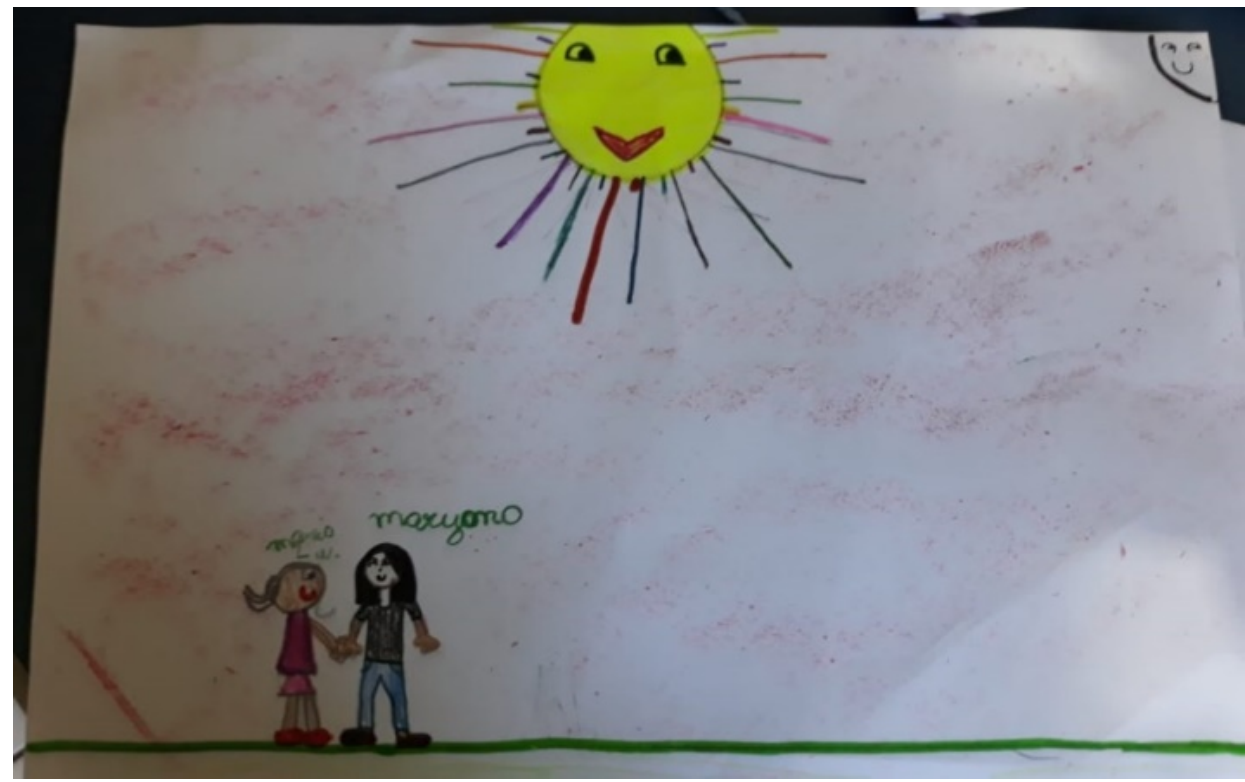

Fonte: Acervo dos(as) pesquisadores(as)

Muitas crianças desenharam situações de amizade ao representar momentos que as deixavam felizes. Na imagem 2, a menina desenhou a si mesma com uma amiga que já havia ido embora da Casa-Lar. Situações como essa são constantes enquanto as crianças se encontram acolhidas. Embora muitas vezes não sintam que aquele é seu lar, as relações entre as crianças se desenvolvem e se aprofundam. $\mathrm{O}$ exemplo da Imagem 2 demonstra como os sentimentos que as crianças têm umas pelas outras no convívio durante o período de acolhimento pode ser alvo de aprendizado e de conscientização a respeito de si mesmas e das relações estabelecidas. Ainda no 
exemplo da Imagem 2, quando uma das crianças representadas no desenho retornou à sua família biológica, sua amiga precisou lidar com a separação, e pôde representar esse sentimento por meio do desenho. Essa situação é comum em Casas-Lares, se considerarmos que quando uma criança ingressa na instituição ou retorna à sua família ou ainda é direcionada a uma família substituta, precisa sempre lidar com a separação e a readaptação ao antigo ou ao novo lar. Diante disso, o aprendizado que ocorre com as diferentes situações vividas pelas crianças se faz em meio às vivências cotidianas e pode ser realizado por meio de práticas pedagógicas enquanto as crianças e adolescentes se encontram abrigados. De acordo com Sastre e Moreno (2002), para se educar civicamente e preparar as crianças para o convívio em sociedade, é necessário priorizar as relações nos processos educativos. Segundo as autoras:

Conhecer os sentimentos e as emoções requer um trabalho cognitivo, já que implica uma conscientização dos próprios estados emocionais, das possíveis causas de cada um deles e de suas consequências, ou seja, de como reagimos quando estamos sob a influência de determinada emoção. (SASTRE; MORENO, 2002, p. 53).

Para que a conscientização dos estados emocionais aconteça, as crianças precisam aprender desde pequenas o motivo de sentirem e aprenderem que os sentimentos são como espelhos que revelam suas atitudes internas e que serão manifestados em seu comportamento. Daí, a necessidade da elaboração e execução de práticas pedagógicas que as auxiliem nesse desenvolvimento (MOSQUERA; STOBÄUS, 2006).

Também houve crianças que atribuíram o sentimento de alegria a objetos, no geral, as menores de 7 anos. Como exemplo, podemos ver a Imagem 3, na qual o menino desenhou alguns presentes e brinquedos que o deixavam feliz.

Imagem 3 - Desenho simbolizando os presentes que deixavam a criança feliz

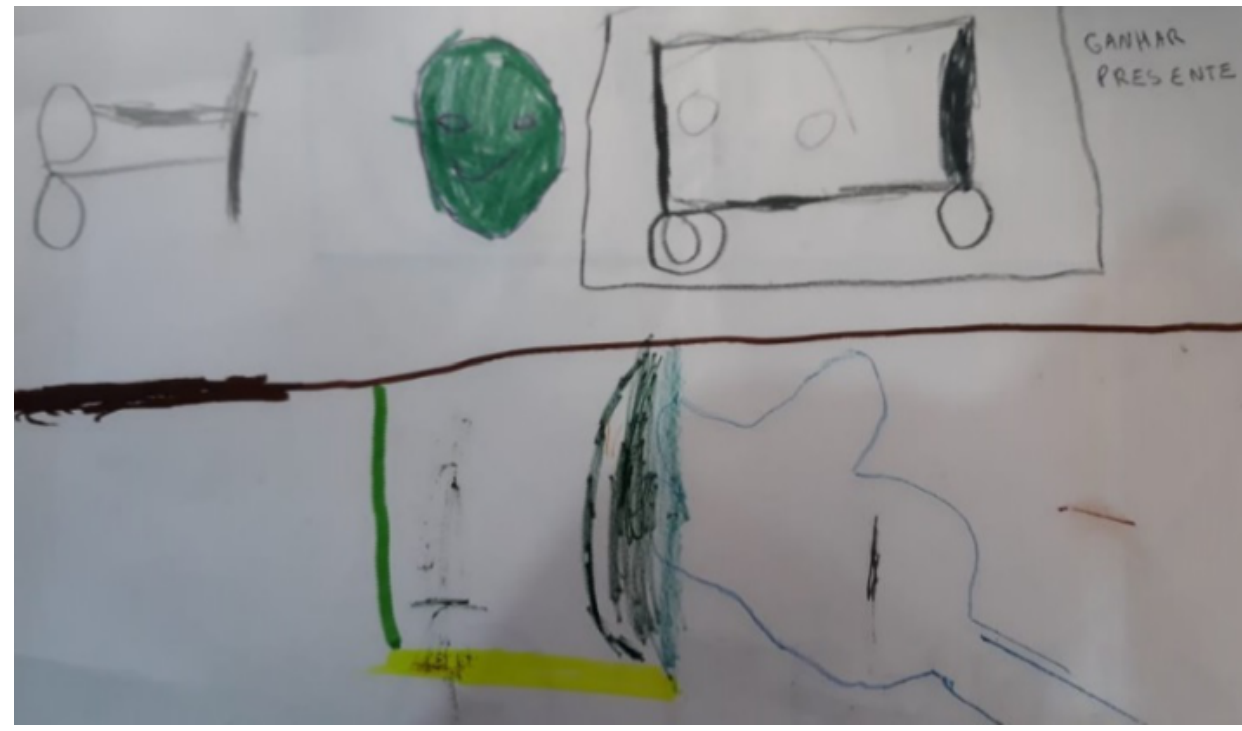

Fonte: Acervo dos(as) pesquisadores(as)

Já na Imagem 4, podemos observar um exemplo do sentimento de tristeza. Assim como outras crianças, o menino desenhou e escreveu sobre ações que já haviam acontecido 
com ele. Desenhou três rostos simbolizando a tristeza e escreveu para cada um deles: "ficou triste porque alguém brigou com ele”; “ficou triste porque alguém bateu nele”; "está triste porque sua mãe morreu e seu pai foi embora”.

Imagem 4 - Imagem representando situações que deixavam o menino triste

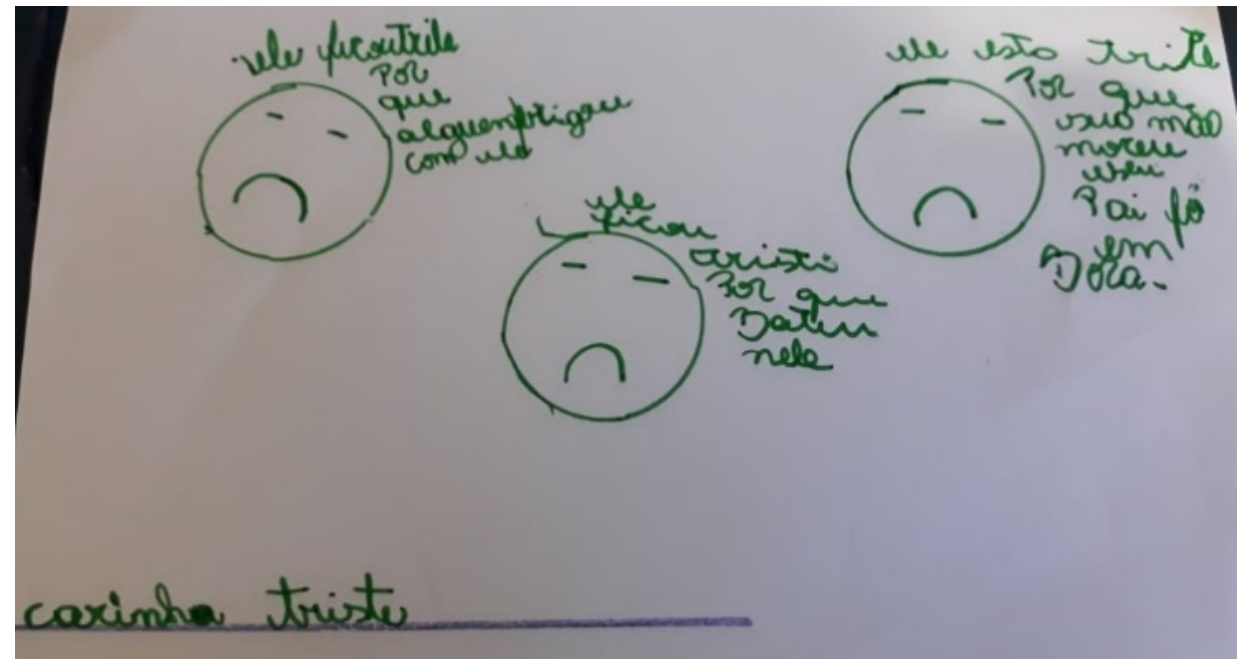

Fonte: Acervo dos(as) pesquisadores(as)

No caso da Imagem 5, a criança nomeou algumas ações que em outros momentos percebemos que ela mesma cometia: xingar, gritar, desobedecer, bater, correr, incomodar e irritar. Dessa forma, percebemos que ao ser estimulada, essa criança fez o exercício de pensar nos sentimentos que permeavam suas ações, o que segundo Sastre e Moreno (2002) é uma possibilidade real para a construção de cidadãos autônomos.

Imagem 5 - Desenho e escrita de coisas que deixavam a criança triste

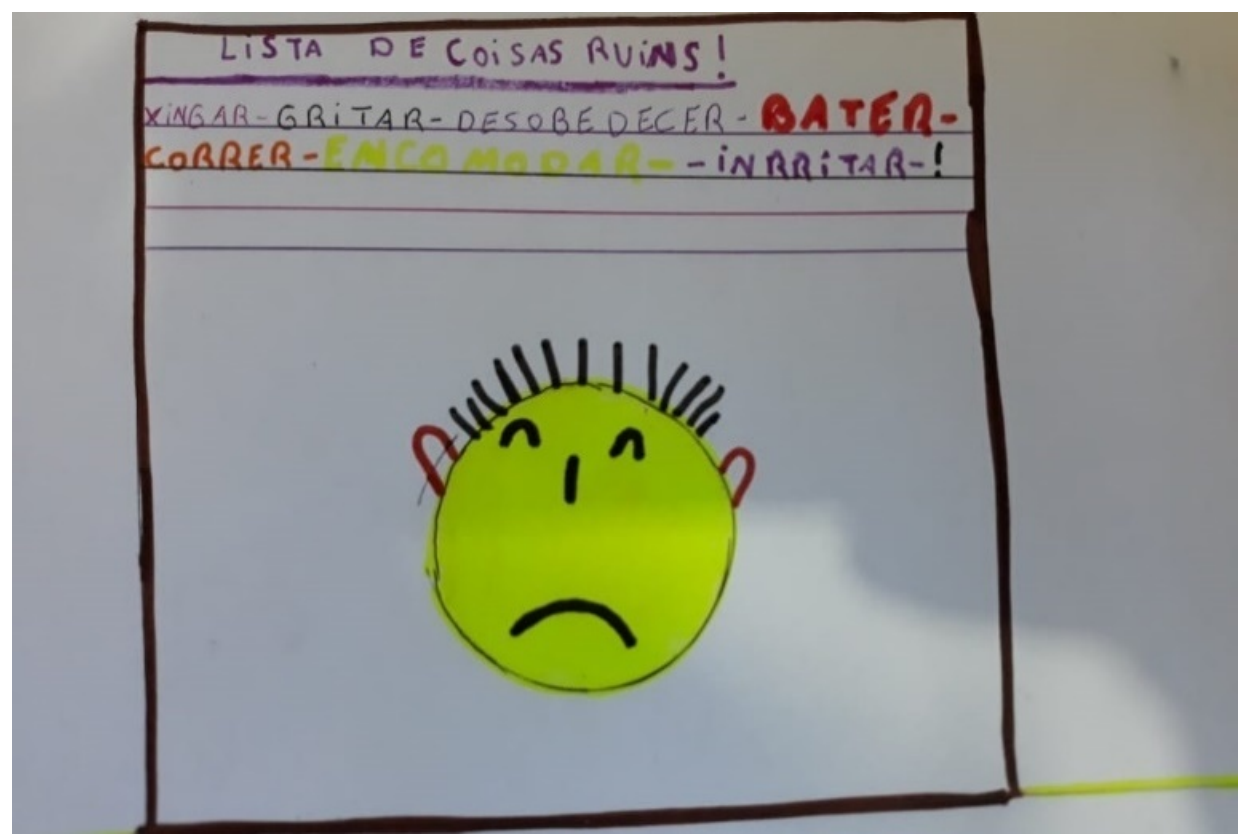

Fonte: Acervo dos(as) pesquisadores(as). 
Percebemos que por mais que os conflitos ocorressem de forma constante na convivência das crianças acolhidas, ao prepararmos ações pedagógicas para que elas refletissem e expressassem seus sentimentos, as crianças puderam reconhecer os motivos de alguns de seus comportamentos. As atividades que foram desenvolvidas mostraram não só a importância da atuação profissional do pedagogo em espaços não escolares como também o potencial que a realização de ações pedagógicas nas Casas-Lares possui para fomentar vias de reflexão sobre os sentimentos nas crianças em situação de vulnerabilidade.

\section{Considerações finais}

Ao ao longo da história brasileira, as crianças que precisaram ser acolhidas foram, muitas vezes, colocadas à margem da sociedade e tiveram seu desenvolvimento comprometido. As medidas de assistência adotadas no Brasil durante os períodos Colonial e Imperial, bem como as medidas repressivas adotadas ao longo do primeiro século da República do Brasil, fizeram com que as instituições de acolhimento se afastassem de um trabalho educativo, sobretudo quando pensamos nos sentimentos e nas ações pedagógicas que podem possibilitar o desenvolvimento integral das crianças e adolescentes acolhidos.

As discussões e leis promulgadas nas últimas décadas a respeito dos direitos das crianças, colocaram as Casas-Lares como espaços potencialmente ricos para a realização de ações pedagógicas nas quais o(a) pedagogo(a) pode trabalhar a fim de auxiliar no desenvolvimento integral das crianças abrigadas.

Ainda que tenham sido conquistados importantes avanços nas últimas três décadas desde a promulgação da Constituição Federal (1988) e do Estatuto da Criança e do Adolescente (1990), ainda são poucos os estudos e pesquisas realizados sobre o papel do(a) pedagogo(a) em instituições de acolhimento. A prática que aqui foi apresentada e realizada na Casa-Lar participante de nossa pesquisa mostrou a importância do(a) pedagogo(a) nas instituições de acolhimento infantil. O exercício possibilitado por meio das ações pedagógicas por nós preparadas mostrou que enquanto estão abrigadas, as crianças e adolescente podem e devem ter acesso a ferramentas que os preparem para a vida comunitária, seja na sua família biológica ou em uma família substituta. Assim, é importante que, ao receberem acolhimento na Casa-Lar ou em famílias adotivas, as crianças tenham condições de pensar em suas próprias ações a fim de desenvolverem sua identidade e se constituírem como pessoas. Em nossa pesquisa, esse foi o foco, além de destacarmos a relevância de um trabalho com sentimentos que não dicotomize razão e emoção. Ainda que seja longo o caminho que estamos trilhando - enquanto nação e também como profissionais da educação - para assegurar os direitos fundamentais à crianças e adolescentes que precisam ser protegidos de toda forma de discriminação, exploração, negligência e violência, vale a pena destacar também que o(a) pedagogo(a) pode contribuir com o trabalho desenvolvido em instituições de acolhimento, atuando diretamente em contato com 
as crianças e adolescentes acolhidas(os) e aproximando ainda mais as instituições de acolhimento aos espaços educativos.

\section{Referências}

ARAÚJO, Ulisses Ferreira; PUIG, José Maria. A construção social e psicológica dos valores. In: ARANTES, Valéria Amorim. Educação e Valores. São Paulo: Summus, 2007.

ARIÈS, Philippe. História Social da Criança e da Família. Rio de Janeiro: Guanabara, 1986.

BERGER, Maria Virginia Bernardi. Aspectos Históricos e Educacionais dos abrigos de crianças e adolescentes: a formação do educador e o acompanhamento dos abrigados. HISTEDBR, Campinas, n. 18, p. 170-185, jun. 2005.

BILAC, Olavo. Ao coração que sofre. Disponível em: $<$ https://www.portalsaofrancisco.com.br/obras-literarias/ao-coracao-que-sofre-2>. Acesso em: 28 nov. 2018.

BRANDÃO, Carlos Rodrigues. Pesquisa participante. São Paulo: Brasiliense, 1981.

BRASIL. Conselho Nacional dos Direitos da Criança e do Adolescente (CONANDA); Conselho Nacional de Assistência Social (CNAS). Orientações técnicas para os serviços de acolhimento para Crianças e Adolescentes. Brasília, 2008.

BRASIL. Constituição da República Federativa do Brasil. Brasília, DF: Senado Federal: Centro Gráfico, 1988. 292 p.

BRASIL. ECA - Estatuto da Criança e do Adolescente. Lei n. 8.069 de 13 de julho de 1990. Brasília, DF: Câmara dos Deputados, Coordenação de publicações, 1990. Disponível em: <http://www.planalto.gov.br/ccivil_03/leis/l8069.htm>. Acesso em: 22 jul. 2020.

CAVALCANTE, Lília Iêda Chaves; CRUZ; Dalízia Amaral. Acolhimento institucional de crianças: qualidade do ambiente e desenvolvimento. In: CAVALCANTE; Lília Iêda Chaves et al. (org) Acolhimento Institucional de crianças e adolescentes: Teorias e evidências científicas para boas práticas. Curitiba: Juruá, 2018. p. 19-36.

CHESINI, Aline Andrioli. Pedagogos(as) em instituições de acolhimento: fazeres e saberes. Dissertação (Mestrado em Educação) - Faculdade de Educação, Universidade Federal do Paraná. Curitiba, p. 153. 2015.

CNJ. Cadastro Nacional de Justiça. Quantidade de acolhimentos por estado. Disponível em: < http://www.cnj.jus.br/cnca/publico/\#>. Acesso em: 09 out. 2019.

DAMÁSIO, António. O erro de Descartes: emoção, razão e o cérebro humano. São Paulo: Companhia das Letras, 2012.

FERRERO, Di; ROCHA, Gee. Razões e emoções. In: Nx Zero. NX ZERO. Universal Music, 2006. Faixa 3. CD.

IZAR, Juliana Gama. A práxis pedagógica em abrigos. Dissertação (Mestrado em Educação). Universidade de São Paulo, São Paulo, 2011.

MORIN, Edgar. Epistemologia da complexidade. In: SCHNITMAN, Dora Fried. Novos paradigmas, Cultura e Subjetividade. Porto Alegre: Artes Médicas, 1996, p. 274-289.

O paradigma de complexidade. In: MORIN, Edgar. Introdução do pensamento complexo. 2 ed. 1990, p. 83-113.

MOSQUERA, Juan José Mouriño; STOBÄUS, Claus Dieter. Afetividade: a manifestação de sentimentos na educação. Educação. Porto Alegre, n. 1 (58), p. 123-133, jan/abr, 2006.

NEJAR, Milene Cristina de Souza. Práticas educativas em Casas-Lares: Relato de uma Intervenção Grupal. 39 f. Monografia apresentada no curso de Especialização em Saúde 
Comunitária. Instituto de Psicologia. Universidade Federal do Rio Grande do Sul, Porto Alegre, 2011.

PARANÁ. Plano decenal dos direitos da criança e do adolescente do estado do Paraná: 2014-2023 / Comitê Interinstitucional para Elaboração, Implementação e Acompanhamento do Plano Decenal dos Direitos da Criança e do Adolescente. (Org.); Secretaria da Família e Desenvolvimento Social (Equipe técnica). Curitiba: SECS, 2013. 450 p.

PÁTARO, Ricardo Fernandes; PÁTARO, Cristina Satiê de Oliveira. "Por que temos sentimentos?”: possibilidades de uma prática voltada para a conscientização dos sentimentos e emoções. Educere et Educare - Revista de Educação, Dossiê: Análise do Comportamento, Educação e Contemporaneidade, Cascavel, V.13, N.25, p. 1-15, jul./dez. $2017 . \quad$ Disponível em: <http://erevista.unioeste.br/index.php/educereeteducare/article/view/16907/11998>. Acesso em: 20 jul. 2020.

RIZZINI, Irene; PILOTTI, Francisco. A Arte de Governar crianças: a história das políticas sociais, da legislação e da assistência à infância no Brasil. 2a . Ed. São Paulo: Cortez, 2009.

RIZZINI, Irene; RIZZINI, Irma. A institucionalização de crianças no Brasil: percursos históricos e desafios do presente. Rio de Janeiro: Ed. PUC-Rio; São Paulo: Loyola, 2004.

SASTRE, Genoveva; MORENO, Montserrat. Resolução de conflitos e aprendizagem emocional: gênero e transversalidade. São Paulo: Moderna, 2002.

SILVA, Enid Rocha Andrade da; MELLO, Simone Gueresi. Um retrato dos abrigos para crianças e adolescentes da rede SAC: Características institucionais, forma de organização e serviços ofertados. In: SILVA, Enid Rocha Andrade da. O direito à convivência familiar e comunitária: os abrigos para crianças e adolescentes no Brasil. Brasilia, 2004. p. 71-96. Disponível em: <www.ipea.gov.br/agencia/images/stories/PDFs/livros/capit3.pdf>. Acesso em: 26 nov. 2018.

SILVA, Bruna Ercoles da; ROSSI, Jean Pablo Guimarães; LANAS, Jesús Ulloa. Crianças acolhidas: questões sobre vínculo afetivo e desenvolvimento infantil - Entrevista com Manuela García Quiroga. Educação e Linguagens, Campo Mourão, v. 7, n. 13, jul/dez. 2018.

TERRA, Márcia Regina. O desenvolvimento humano na teoria de Piaget. Disponível em: $<$ https://www.unicamp.br/iel/site/alunos/publicacoes/textos/d00005.htm>. Acesso em: 27 nov. 2018.

TORRES, Diana de Farias. A educação de crianças residentes em abrigos. Interação, São Paulo. v. 1, ed. 15, p. 50-62, 2015.

TRILLA, Jaume. A educação não formal. In: ARANTES, Valéria Amorim (org.). Educação formal e não-formal: pontos e contrapontos. São Paulo: Summus, 2008.

Recebido em: 09/10/2019

Aprovado em: 13/07/2020 